\title{
Role of the renal sympathetic nerves in renal sodium/potassium handling and renal damage in spontaneously hypertensive rats
}

\author{
JIANLING LI ${ }^{1}$, QIAOLING HE ${ }^{2}$, WEIFENG WU ${ }^{1}$, QINGJIE LI ${ }^{1}$, \\ RONGJIE HUANG ${ }^{1}$, XIAOFENG PAN ${ }^{1}$ and WENYING LAI ${ }^{1}$ \\ ${ }^{1}$ Department of Cardiology, First Affiliated Hospital of Guangxi Medical University, Nanning, Guangxi 530021; \\ ${ }^{2}$ Department of Pharmacology, Affiliated Hospital of Guangxi Medical University, \\ The First People's Hospital of Nanning, Nanning, Guangxi 530000, P.R. China
}

Received March 26, 2015; Accepted May 12, 2016

DOI: $10.3892 /$ etm.2016.3669

\begin{abstract}
Renal sympathetic nerve activity has an important role in renal disease-associated hypertension and in the modulation of fluid homeostasis. In the present study, changes in renal function and renal sodium/potassium handling were investigated in groups of 12 -week-old male, spontaneously hypertensive rats with renal denervation (RDNX group) or sham denervation (sham group). The RDNX group excreted significantly more sodium than the sham group during the 2 -week observation period $(\mathrm{P}<0.05)$. Following bilateral renal denervation, the fractional lithium excretion was elevated in the RDNX group compared with the sham group, but no significant effect was observed of renal denervation on the fractional distal reabsorption rate of sodium or the fractional excretion of potassium. Furthermore, the glomerular injury score and the wall-to-lumen ratio of the interlobular artery were significantly lower in the RDNX group than in the sham group $(\mathrm{P}<0.05)$. In conclusion, the present study indicates an involvement of the renal sympathetic nerves in the regulation of renal tubular sodium reabsorption in spontaneously hypertensive rats and in the renal damage associated with hypertension.
\end{abstract}

\section{Introduction}

Hypertension causes renal injury and is a major factor inducing progressive organ damage in end-stage renal disease (1). Sympathetic nerve activity (SNA) is increased in patients with chronic kidney disease and has an important and distinct role in renal disease-associated hypertension (2,3). A long-standing hypothesis proposes that neurogenic hypertension results from

Correspondence to: Professor Weifeng Wu, Department of Cardiology, First Affiliated Hospital of Guangxi Medical University, 6 Shuangyong Road, Nanning, Guangxi 530021, P.R. China

E-mail:wucna65@163.com

Key words: renal denervation, sympathetic nerve activity, hypertension, renal sodium/potassium handling, renal function alterations to renal function via the actions of renal nerves on renal vascular resistance, tubular sodium reabsorption and renin release $(4,5)$. Catheter-based renal denervation (RD) has been introduced into clinical practice to selectively denervate efferent and afferent renal sympathetic fibers (6-8). Other than resulting in marked and sustained blood pressure reductions, $\mathrm{RD}$ has also been demonstrated to reduce renal resistive index, and the incidence of albuminuria without adversely affecting glomerular filtration rate or renal artery structure (9).

The kidneys are critical to the regulation of blood pressure via modulation of sodium and water excretion (10). One mechanism by which the kidneys are posited to maintain fluid homeostasis is using the renal sympathetic nerves (11). RD is widely reported to cause an increase in sodium, potassium and water excretion in several mammalian species (12-15). However, controversy remains regarding the immediate changes to renal excretory functions following RD $(15,16)$. No appreciable differences were observed by Salman et al in the mean arterial pressure (MAP) and plasma sodium (PNa) between denervated and innervated SD rats $(15,16)$.

In the present study, the changes to renal function and renal sodium/potassium handling were investigated in spontaneously hypertensive rats (SHR) subjected to RD, with the aim of functionally characterizing the sympathetic nerve control of the kidney. The current study addressed this aim using a correlation of renal sodium/potassium excretions and renal function by combining surgical and chemical procedures to achieve RD.

\section{Materials and methods}

Animals. All experimental procedures conformed to the Animal Ethics Committee guidelines of Guangxi Medical University (Nanning, China), and received committee approval. Twelve-week-old male SHR ( $\mathrm{n}=16$ animals) and age-matched Wistar Kyoto (WKY) rats ( $n=8$ animals) were obtained from Vital River Laboratories Co., Ltd. (Beijing, China). The animals were housed in controlled environmental conditions consisting of a 12-h light/dark cycle and $22 \pm 2{ }^{\circ} \mathrm{C}$. All animals were fed ad libitum throughout the study with standard rat chow (Vital River Laboratories Co., Ltd.) for at least seven days before the study. Following an acclimation 
period of two weeks, SHR were randomly assigned to the renal denervated (RDNX; $n=8)$ or sham $(n=8)$ groups.

Surgical preparation of animal and experimental protocol. Rats were fasted overnight prior to the surgery. Briefly, anesthesia was induced using pentobarbital sodium at a dose of $50 \mathrm{mg} / \mathrm{kg}$ (intraperitoneally; Sigma-Aldrich, St. Louis, MO, USA), and the kidneys were exposed through midline abdominal incisions and surgically denervated with the aid of a stereomicroscope (Shanghai Third Optical Instrument Factory, Shanghai, China). Denervation was accomplished by incising all visible nerves along the renal artery, and the renal vessels were surrounded with cotton swabs previously soaked in $10 \%$ (v/v) phenol solution (Shanghai Biological Engineering Co., Ltd., Shanghai, China) for 2 min. Sham RD (sham group) treatment entailed identical anesthetic and surgical procedures, but the renal nerves were left intact. After two weeks, tail arterial pressure was estimated by the tail-cuff method (17), and urine was collected over $24 \mathrm{~h}$. Under anesthesia with $200 \mathrm{mg} / \mathrm{kg}$ ketamine (intramuscular injection; Jiang Su Heng Rui Medicine Co., Ltd., Suzhou, China), blood was drawn via abdominal aortic puncture, and the kidneys were removed.

Serum and urine lithium concentrations were measured with an AA-7000 atomic absorption spectrometer (Shimadzu, Kyoto, Japan), while serum and urine sodium, potassium, protein and creatinine concentrations were determined by spectrophotometer (Roche Diagnostics, Basel, Switzerland). To confirm that the chemical RD was achieved in the rats, renal tissue and serum noradrenaline (NE) content was analyzed in each experimental group using high-performance liquid chromatography (HPLC) with electrochemical detection (ECD) (LC-20A; Shimadzu).

Calculations. Urine flow rate (UFR) was calculated by the following formula: UFR $(\mu \mathrm{l} / \mathrm{min} / \mathrm{kg})=\mathrm{UV} / \mathrm{T} \times \mathrm{BW}$, in which $\mathrm{UV}(\mu \mathrm{l})$ is the urine volume, $\mathrm{T}(\mathrm{min})$ is the time and $\mathrm{BW}(\mathrm{kg})$ is the body weight of the rat (16).

The clearances were calculated using the usual formula: $\mathrm{Cx}=\mathrm{Ux} \mathrm{x} \mathrm{UFR} / \mathrm{Sx}$, in which $\mathrm{Cx}$ is the clearance of substance ' $\mathrm{x}$ ', $\mathrm{Ux}$ is the urine concentration of ' $\mathrm{x}$ ' and $\mathrm{Sx}$ is the serum concentration of ' $x$ '. Glomerular filtration rate $(\mathrm{Ccr})$ was considered to indicate the clearance of creatinine. The fractional excretion of ' $\mathrm{x}$ ' (FEx) was calculated as: $\mathrm{Cx} / \mathrm{Ccr}$. The fractional distal reabsorption rate of sodium was calculated by the following formula: $\mathrm{FDR}_{\mathrm{Na}}=\left[\left(\mathrm{FE}_{\mathrm{Li}}-\mathrm{FE}_{\mathrm{Na}}\right) / \mathrm{FE}_{\mathrm{Li}}\right] \mathrm{x} 100 . \mathrm{FE}_{\mathrm{Li}}$ and $\mathrm{FDR}_{\mathrm{Na}}$ were calculated as markers of proximal and distal sodium handling, respectively (18). $\mathrm{FE}_{\mathrm{Li}}=\mathrm{U}_{\mathrm{Li}} \times \mathrm{Scr} / \mathrm{S}_{\mathrm{Li}} \times \mathrm{U}_{\mathrm{cr}}$. Serum and urine sodium, potassium, protein and creatinine concentrations were determined using a spectrophotometer (Roche Diagnostics) and lithium concentration by inductively coupled plasma mass spectrometry (7500CE; Agilent Technologies, Inc., Santa Clara, CA, USA).

Histological examination. Kidney tissues (coronal slices) were fixed with $10 \%$ paraformaldehyde and embedded in paraffin (Shanghai Biological Engineering Co., Ltd.). Coronal sections of the kidney (4- $\mu$ m-thick) were stained with periodic acid-Schiff and Masson-trichrome stains (Fuzhou Maixin Biotech, Co., Ltd., Fuzhou, China), and examined blind using a DP72 brightfield microscope (Olympus Corporation,
Tokyo, Japan) to assess glomerular and arterial morphology. Histological scores were assessed using Image-Pro Plus version 6.0 software (Media Cybernetics, Inc., Rockville, MD, USA). Glomerular injury score was calculated as previously described $(19,20)$. At least 50 glomeruli were randomly selected in each rat and the mean glomerular injury score was calculated. The severity of tubulointerstitial injury was evaluated by the interstitial fibrosis (IF) score, as described previously $(19,20)$. The percentage of interstitial fibrotic areas per cortical field (magnification, x100) was calculated, and the mean percentage from 10 randomly selected fields of view was determined as the IF score for each rat. The medial thickness-to-lumen ratio was calculated as described previously (21). For this, 5 regions of the interlobular artery from each rat were evaluated, and the average ratio was calculated.

Statistical analysis. Values are presented as mean \pm standard error. Statistical analysis was performed using SPSS 16.0 software (SPSS, Inc., Chicago, IL, USA). Comparisons between multiple groups were evaluated using one-way analysis of variance followed by the Dunnett test. $\mathrm{P}<0.05$ was considered to represent a statistically significant difference.

\section{Results}

General observations. The body weights of the rats were similar in all three groups (RDNX group, $231 \pm 15 \mathrm{~g}$; sham group, $238 \pm 13 \mathrm{~g}$; and WKY group, $229 \pm 16 \mathrm{~g}$ ). RD was confirmed by assessment of renal tissue and serum NE content (Table I). As Table I shows that serum NE content was significantly lower in RDNX compared with the sham group $(\mathrm{P}<0.05)$, and did not differ between the RDNX and WKY groups. The kidney NE content was significantly lower in the RDNX group compared with the sham group $(\mathrm{P}<0.05)$, and did not differ between the RDNX and WKY groups. No significant differences in serum sodium, potassium or creatinine, and serum or urine protein concentrations were observed among the three groups. There was no observably significant difference in Ccr among the three groups. The kidney weight/body weight ratio of the rats was not affected by bilateral renal denervation (RDNX group, $3.515 \pm 0.14 \mathrm{~g} / \mathrm{kg}$; sham group, $3.64 \pm 0.29 \mathrm{~g} / \mathrm{kg}$; and WKY group, $3.5 \mathrm{ww} 6 \pm 0.23 \mathrm{~g} / \mathrm{kg}$ ).

Effects of $R D$ on renal sodium/potassium excretions. $\mathrm{FE}_{\mathrm{K}}$ was lower in the RDNX group compared with the sham group, but no significant difference in $\mathrm{FE}_{\mathrm{K}}$ was found among the three groups (Table I). RD generated a significantly $(\mathrm{P}<0.05)$ higher sodium clearance $\left(\mathrm{C}_{\mathrm{Na}}\right)$ compared with the sham group (Fig. 1). Sham and WKY groups showed significant differences for $\mathrm{FE}_{\mathrm{K}}$ and $\mathrm{C}_{\mathrm{Na}}$. Furthermore, the FELi was significantly $(\mathrm{P}<0.05)$ higher in the RDNX group compared with the sham group. $\mathrm{FE}_{\mathrm{K}}, \mathrm{C}_{\mathrm{Na}}$ and $\mathrm{FE}_{\mathrm{Li}}$ exhibited no significant differences between the RDNX and WKY groups. In contrast with these observations, RD did not significantly alter $\mathrm{FDR}_{\mathrm{Na}}(\mathrm{P}>0.05)$ in SHRs compared with the sham group.

Effects of RD on renal histopathology. Less glomerular morphological change, assessed by the glomerular injury score, was noted in the RDNX group compared with the sham group (Fig. 2). The glomerular injury score was lower in the 
Table I. Parameters of renal function and sodium handling in rats.

\begin{tabular}{|c|c|c|c|c|}
\hline Parameter & RDNX & Sham & WKY & P-value \\
\hline $\mathrm{Kw} / \mathrm{Bw}, \mathrm{g} / \mathrm{kg}$ & $3.515 \pm 0.14$ & $3.64 \pm 0.29$ & $3.56 \pm 0.23$ & 0.31 \\
\hline MAP, mmHg & $96 \pm 7^{\mathrm{a}}$ & $131 \pm 10$ & $89 \pm 8^{a}$ & $<0.05$ \\
\hline $\mathrm{S}-\mathrm{NE}, \mathrm{ng} / \mathrm{ml}$ & $14.02 \pm 2.37^{\mathrm{a}}$ & $23.04 \pm 8.77$ & $13.41 \pm 3.95^{\mathrm{a}}$ & $<0.05$ \\
\hline $\mathrm{K}-\mathrm{NE}, \mathrm{ng} / \mathrm{mg}$ & $0.95 \pm 0.21^{\mathrm{a}}$ & $1.35 \pm 0.18$ & $1.01 \pm 0.24^{\mathrm{a}}$ & $<0.05$ \\
\hline $\mathrm{S}-\mathrm{Na}, \mathrm{mmol} / \mathrm{l}$ & $142.78 \pm 1.09$ & $142.12 \pm 1.36$ & $141.43 \pm 1.22$ & 0.67 \\
\hline $\mathrm{S}-\mathrm{K}, \mathrm{mmol} / \mathrm{l}$ & $4.56 \pm 0.29$ & $4.88 \pm 0.32$ & $4.51 \pm 0.24$ & 0.17 \\
\hline $\mathrm{S}-\mathrm{Cr}, \mathrm{mmol} / \mathrm{l}$ & $30.78 \pm 3.96$ & $32.88 \pm 4.09$ & $34.00 \pm 3.21$ & 0.26 \\
\hline S-Pro, g/l & $55.16 \pm 7.68$ & $57.19 \pm 5.31$ & $60.57 \pm 8.60$ & 0.23 \\
\hline U-Pro, mg/24 h & $2.35 \pm 0.42$ & $2.35 \pm 0.74$ & $2.07 \pm 0.47$ & 0.54 \\
\hline $\mathrm{FE}_{\mathrm{K}}, \%$ & $47.04 \pm 4.80$ & $52.77 \pm 4.78$ & $45.75 \pm 6.41$ & 0.19 \\
\hline $\mathrm{FE}_{\mathrm{Li}}, \%$ & $18.13 \pm 2.21^{\mathrm{a}}$ & $15.24 \pm 1.78$ & $17.35 \pm 2.17^{\mathrm{a}}$ & 0.03 \\
\hline $\mathrm{C}_{\mathrm{Na}}, \mu 1 / \mathrm{min}$ & $5.39 \pm 1.83^{\mathrm{a}}$ & $3.63 \pm 1.27$ & $5.59 \pm 1.97^{\mathrm{a}}$ & 0.04 \\
\hline $\mathrm{FDR}_{\mathrm{Na}}, \%$ & $94.55 \pm 9.33$ & $94.21 \pm 7.01$ & $93.97 \pm 10.65$ & 0.08 \\
\hline $\mathrm{Ccr}, \mathrm{ml} / \mathrm{min} \cdot \mathrm{kg}$ & $0.48 \pm 0.13$ & $0.45 \pm 0.15$ & $0.52 \pm 0.14$ & 0.60 \\
\hline
\end{tabular}

Values are reported as the mean \pm standard error $(n=8)$. Kw, kidney weight; Bw, body weight; MAP, mean arterial pressure; S-NE, serum noradrenaline content; K-NE, kidney noradrenaline content; S-Na, serum sodium; S-K, serum potassium; S-Cr, serum creatinine; S-Pro, serum total protein; U-Pro, urinary protein; $\mathrm{FE}_{\mathrm{K}}$, fractional excretion of potassium into urine; $\mathrm{FE}_{\mathrm{Li}}$, fractional excretion of lithium into urine; $\mathrm{C}_{\mathrm{Na}}$, sodium clearance; $\mathrm{FDR}_{\mathrm{Na}}$, fractional distal reabsorption rate of sodium; Ccr, creatinine clearance. ${ }^{\mathrm{a}} \mathrm{P}<0.05$ vs. sham group.
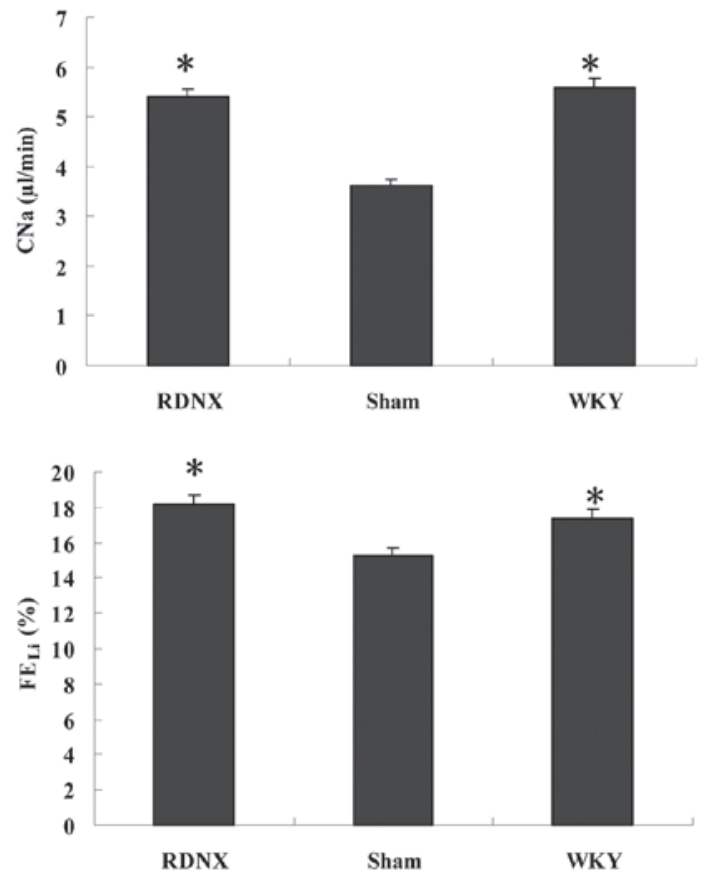

Figure 1. $\mathrm{C}_{\mathrm{Na}}$ and $\mathrm{FE}_{\mathrm{Li}}$ in rats. $\mathrm{C}_{\mathrm{Na}}$, sodium clearance; $\mathrm{FE}_{\mathrm{Li}}$, fractional lithium excretion. Data are reported as the mean \pm standard error of the mean. ${ }^{*} \mathrm{P}<0.05$ vs. sham group.

RDNX group than in the sham group $(2.5 \pm 0.1$ vs. $0.7 \pm 0.2$, respectively; $\mathrm{P}<0.05)$. To assess changes to the interlobular artery, a parameter of hypertension-related vascular damage, the wall-to-lumen ratio was examined. The medial thickness-to-lumen diameter ratio was higher in the sham group than in the WKY group, indicating that this had been caused by sham treatment (Fig. 3). RD significantly decreased the ratio to a similar level as that of the WKY group. The severity of tubulointerstitial injury was evaluated by IF score, revealing no significant difference in IF score among the three groups (Fig. 4).

\section{Discussion}

Renal sympathetic nerves utilize NE as a neurotransmitter, which affects the renal arterioles, juxtaglomerular granular cells and tubules of the kidney (22). Using a rat model of genetic hypertension, several manifestations of renal sodium excretion, glomerular and arterial morphological structure was reported in the present study to be substantially alleviated when RD is performed by chemical sympathectomy.

In the current study, SHRs were selected due to previous evidence of increased renal sympathetic discharge in this hypertension model (23). The kidney has an important role in the regulation of blood pressure via modulation of sodium and water excretion (10). A previous study of SHRs suggested that an impaired pressure-diuresis relationship exists in these animals, such that greater perfusion pressures are required to achieve the same level of diuresis when compared with WKY rats (24). Furthermore, a previous study using isolated perfused kidneys from SHRs revealed an intrinsic renal abnormality in sodium excretion that may contribute to the maintenance of hypertension in SHR (25). Renal sympathetic nerves and circulating catecholamine are involved in the regulation of sodium and water excretion in the kidney (26). In the present study, a significant change to sodium excretion was observed following RD. Higher $\mathrm{C}_{\mathrm{Na}}$ was observed in the denervated SHRs compared with rats with intact renal nerves. The observed natriuresis following RD has been reported in several studies on acute and chronic RD of different experimental hypertensive rats $(21,27,28)$. Together, these 

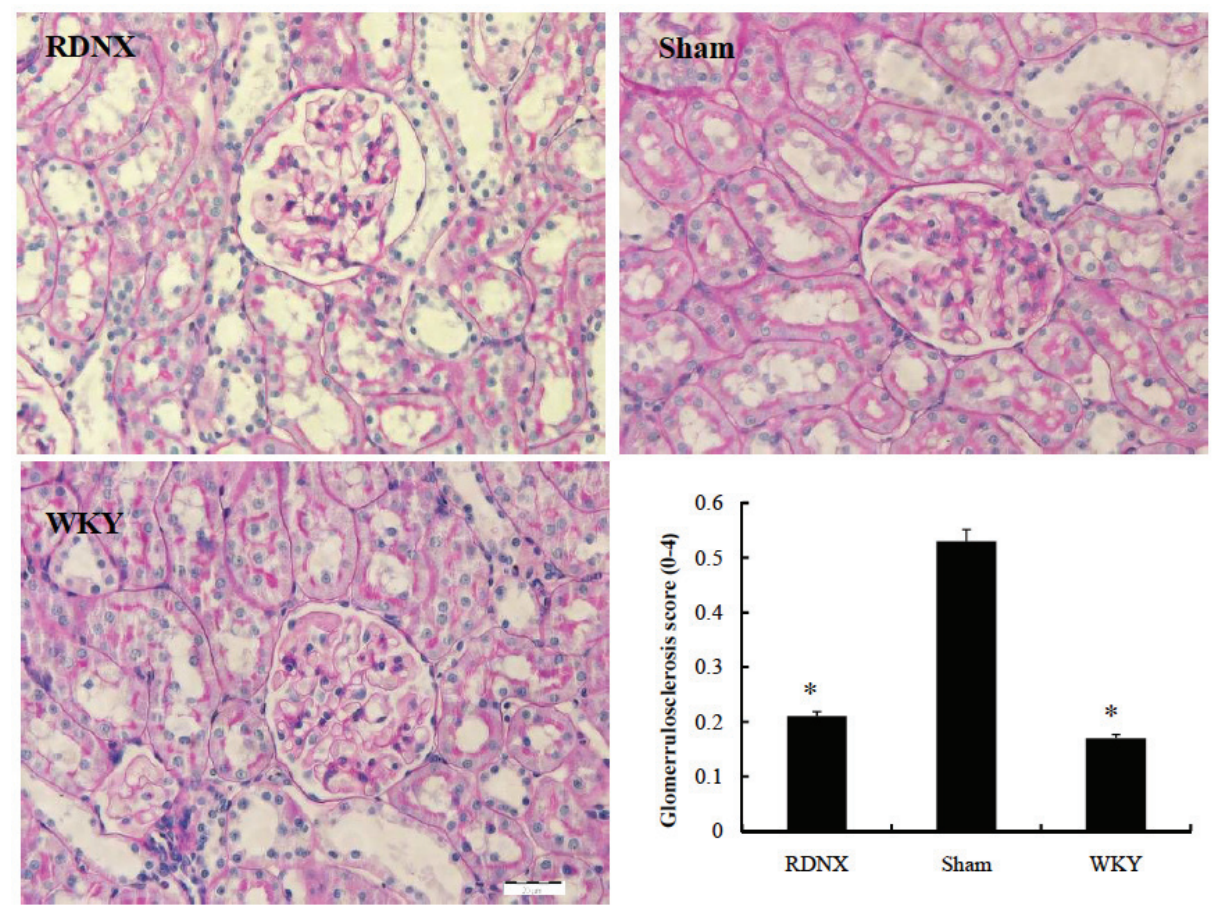

Figure 2. Changes in the glomeruli following renal denervation, detected using periodic acid-Schiff staining. Glomerular injury caused by mesangial expansion was graded from 0 to 4 . At least 50 glomeruli, selected at random, were assessed from each rat and the mean scores were calculated and compared. ${ }^{*} \mathrm{P}<0.05$ vs. sham group.
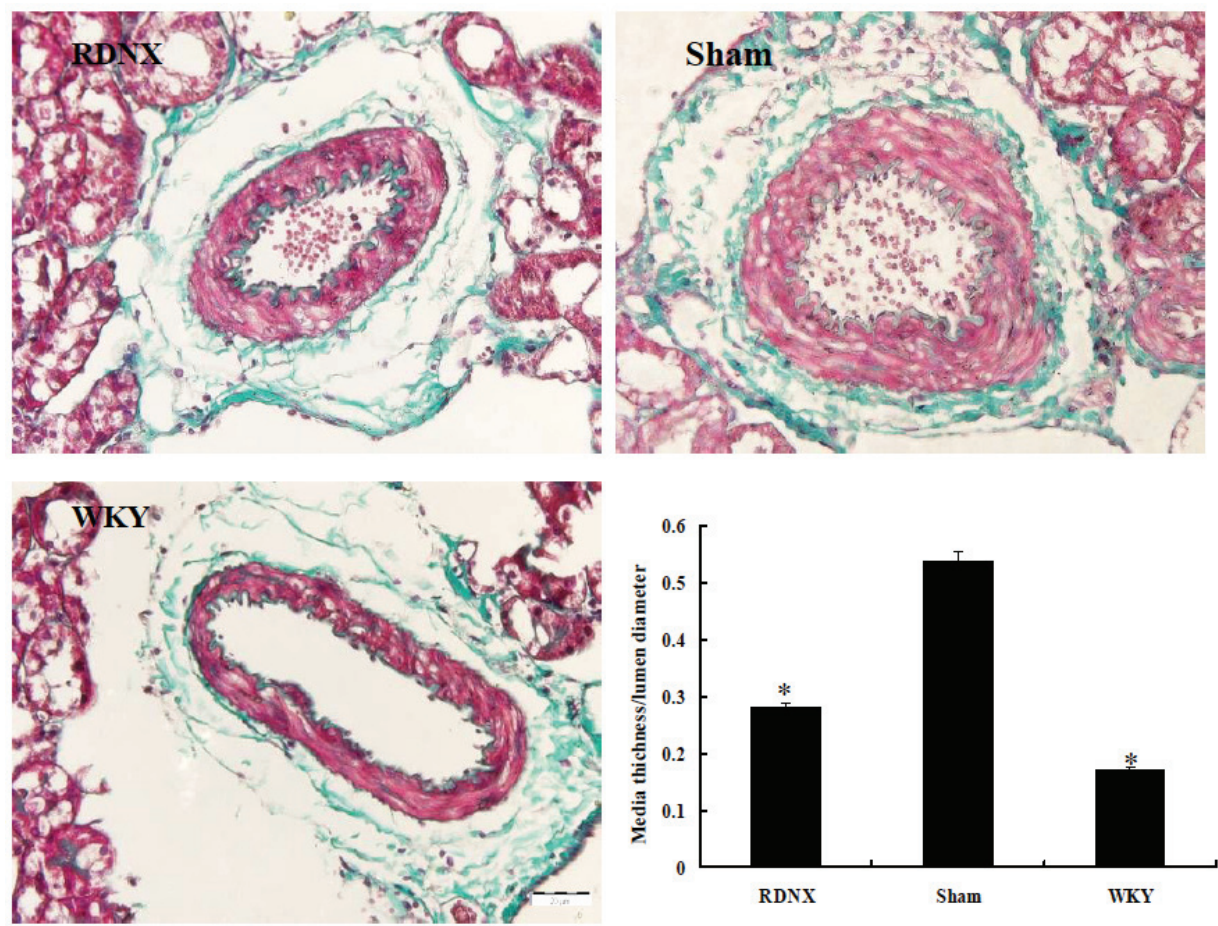

Figure 3. Changes in the interlobular artery following renal denervation, observed using Masson staining. The interlobular artery was identified as a single muscular artery within the inner cortex, sometimes appearing adjacent to the glomerulus. Five arteries were examined from each rat, from which the medial thickness-to-lumen ratio was averaged for each rat and group means were calculated and compared. ${ }^{*} \mathrm{P}<0.05 \mathrm{vs}$. sham group.

and previous results implicated renal sympathetic activity in sodium regulation (16).

It has previously been revealed that NE released from renal sympathetic nerve endings acts on the basolateral membranes of epithelial cells to stimulate tubular sodium and water reabsorption at the proximal tubule, thick ascending limb of the loop of Henle and the distal nephron (29). Electric stimulation of the renal nerves in acute experiments has been demonstrated to enhance sodium reabsorption, particularly in the proximal convoluted tubule. Low-frequency renal nerve 

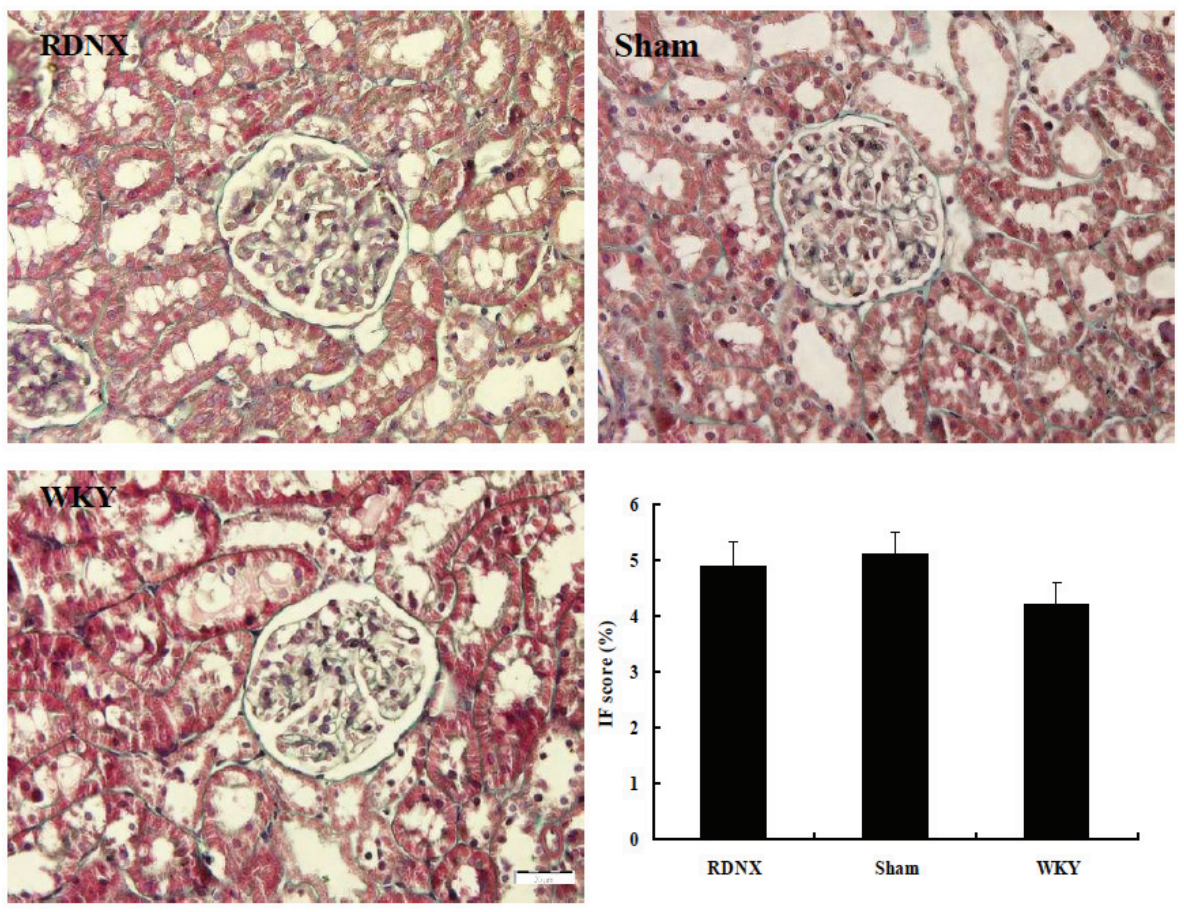

Figure 4. Histology of the tubulointerstitium, detected by Masson staining. The severity of tubulointerstitial injury was evaluated by IF score. The percentage of interstitial fibrotic areas per cortical field (magnification, $\mathrm{x} 400$ ) was calculated, and the mean percentage in 10 randomly selected fields was determined as the IF score for each rat. No significant differences were observed in IF score among the three groups.

stimulation directly affects proximal tubular sodium reabsorption and rennin release in the absence of changes to renal hemodynamics (30). Furthermore, several previous studies indicated that RD results in an increased urine flow rate that is attributed to a decreased absolute and fractional reabsorption of sodium in the proximal convoluted tubule $(31,32)$. Conversely, several previous studies have reported that bilateral RD in 3- to 8-week-old SHRs delays the development of hypertension, associated with reduced sodium reabsorption by the proximal tubule, the loop of Henle and the distal convolution (33-35). In the present study, following bilateral RD, $\mathrm{FE}_{\mathrm{Li}}$ was elevated when compared with the sham-operated group, consistent with the withdrawal of sympathetic stimulation. While the results of the present study indicated no significant effect of RD on $\mathrm{FDR}_{\mathrm{Na}}$, it may be that RD results in decreased sodium reabsorption by the proximal convoluted tubule, but not the distal convoluted tubule.

The renal mechanisms of potassium excretion have varied upon the application of a diversity of techniques including renal clearance, micropuncture, microperfusion and electrophysiological studies (15). However, a paucity of information exists on the role of the adrenergic mechanisms in the regulation of renal potassium reabsorption and secretion. It is established that potassium freely diffuses in the renal corpuscular membrane, and the majority of its filtered load is reabsorbed by proximal tubular epithelial cells. However, potassium excretion in the urine depends on controlled secretion in the distal nephron (36). Salman et al (15) demonstrated that RD in Sprague Dawley rats caused a significantly higher renal potassium excretion in absolute terms and as a fraction of the filtered load. However, the present study did not report significant changes to plasma potassium levels and urinary potassium excretion, suggesting that decreased renal sympathetic nerve activity of SHR has a more direct tubule natriuretic effect in the proximal segment than at the sodium-potassium exchange site.

Hypertension is an established consequence of chronic renal disease, and is often observed in patients with focal segmental glomerulosclerosis and with membranoproliferative glomerulonephritis (37). Furthermore, several lines of evidence suggest that sympathetic overactivity, through functional and morphological alterations to renal physiology and structure, may contribute to kidney injury and chronic kidney disease progression (38). In the present study, renal sympathetic denervation aided amelioration of glomerular sclerosis in SHR. To assess changes to the small arteries, a parameter of hypertension-related vascular damage, the wall-to-lumen ratio was examined. The current data indicated that RD not only reverses glomerular sclerosis, but also greatly enlarges the lumen size of the interlobular artery in these genetically hypertensive rats. There is much experimental evidence and clinical data to indicate that drugs that reduce SNA have a renoprotective effect. Moxonidine, which decreases sympathetic nerve activity, was revealed to have renoprotective effects in patients, in addition to in experimental rats with renal failure (39-41). Furthermore, catheter-based RD selectively targets efferent and afferent renal nerves and functionally denervates the kidney, reducing blood pressure in clinical trials (38), and provide renoprotection in diabetic and Dahl salt-sensitive rats by ameliorating the effects of excessive renal sympathetic signals $(3,42)$. Together, these observations confirm that RD considerably improves glomerular sclerosis and hypertension-associated renal vascular damage, which indicates a role of the overactive sympathetic nervous system in this pathophysiological state.

In conclusion, the present data demonstrate that renal nerves are significantly involved in the regulation of renal tubular 
sodium reabsorption in SHR. Furthermore, if the kidney is prevented from sympathetic nerve stimulation, structural changes due to early stage hypertensive nephropathy, namely glomerular sclerosis and vascular damage, are abolished.

\section{Acknowledgements}

The present study was supported by research funding from Guangxi Provincial Education Office (grant no. 201202ZD025), the Opening Project of the Science Experiment Center, Guangxi (grant no. KFJJ2011-35) and the National Natural Science Foundation of Guangxi (grant no. 2012GXNSFAA239004).

\section{References}

1. Bakris GL, Williams M, Dworkin L, Elliott WJ, Epstein M, Toto R, Tuttle K, Douglas J, Hsueh W and Sowers J: Preserving renal function in adults with hypertension and diabetes: A consensus approach. National kidney foundation hypertension and diabetes executive committees working group. Am J Kidney Dis 36: 646-661, 2000.

2. Neumann J, Ligtenberg G, Klein II, Koomans HA and Blankestijn PJ: Sympathetic hyperactivity in chronic kidney disease: Pathogenesis, clinical relevance and treatment. Kidney Int 65: 1568-1576, 2004.

3. Nagasu H, Satoh M, Kuwabara A, Yorimitsu D, Sakuta T, Tomita N and Kashihara N: Renal denervation reduces glomerular injury by suppressing $\mathrm{NAD}(\mathrm{P}) \mathrm{H}$ oxidase activity in dahl salt-sensitive rats. Nephrol Dial Transplant 25: 2889-2898, 2010.

4. DiBona GF and Kopp UC: Neural control of renal function. Physiol Rev 77: 77-197, 1997.

5. Guyton AC, Coleman TG, Cowley AW, Scheel KW, Manning RD and Norman RA: Arterial pressure regulation: Overriding dominance of the kidneys in long-term control and in hypertension. Am J Med 52: 584-594, 1972.

6. Krum H, Schlaich M, Whitbourn R, Sobotka PA, Sadowski J, Bartus K, Kapelak B, Walton A, Sievert H, Thambar S, et al Catheter-based renal sympathetic denervation for resistant hypertension: A multicentre safety and proof-of-principle cohort study. Lancet 373: 1275-1281, 2009.

7. Symplicity HTN-2 Investigators: Esler MD, Krum H, Sobotka PA, Schlaich MP, Schmieder RE and Böhm M: Renal sympathetic denervation in patients with treatment-resistant hypertension (The Symplicity HTN-2 Trial): A randomised controlled trial. Lancet 376: 1903-1909, 2010.

8. Krum H, Sobotka P, Mahfoud F, Böhm M, Esler M and Schlaich M: Device-based antihypertensive therapy: Therapeutic modulation of the autonomic nervous system. Circulation 123: 209-215, 2011.

9. Mahfoud F, Cremers B, Janker J, Link B, Vonend O, Ukena C, Linz D, Schmieder R, Rump LC, Kindermann I, et al: Renal hemodynamics and renal function after catheter-based renal sympathetic denervation in patients with resistant hypertension. Hypertension 60: 419-424, 2012.

10. Guyton AC: Blood pressure control-special role of the kidneys and body fluids. Science 252: 1813-1816, 1991.

11. Jacob F, Ariza P and Osborn JW: Renal denervation chronically lowers arterial pressure independent of dietary sodium intake in normal rats. Am J Physiol Heart Circ Physiol 284: H2302-H2310, 2003.

12. Bonjour JP, Churchill PC and Malvin RL: Change of tubular reabsorption of sodium and water after renal denervation in the dog. J Physiol 204: 571-582, 1969.

13. Blake WD and Jurf AN: Renal sodium reabsorption after acute renal denervation in the rabbit. J Physiol 196: 65-73, 1968.

14. Boer PA, Morelli JM, Figueiredo JF and Gontijo JA: Early altered renal sodium handling determined by lithium clearance in spontaneously hypertensive rats (SHR): Role of renal nerves. Life Sci 76: 1805-1815, 2005.

15. Salman IM, Sattar MA, Abdullah NA, Ameer OZ, Basri F, Hussain NM, Yam MF, Swarup KR, Rathore HA, Kazi RN, et al: Role of renal sympathetic nervous system in the control of renal potassium handling. J Nephrol 23: 291-296, 2010.
16. Salman IM, Sattar MA, Abdullah NA, Ameer OZ, Hussain FB, Hye Khan MA, Yam MF, Rathore KR, Kazi RN, Salman HM and Johns EJ: Renal functional \& haemodynamic changes following acute unilateral renal denervation in sprague dawley rats. Indian J Med Res 131: 76-82, 2010.

17. Kubota Y, Umegaki K, Kagota S, Tanaka N, Nakamura K, Kunitomo M and Shinozuka K: Evaluation of blood pressure measured by tail-cuff methods (without heating) in spontaneously hypertensive rats. Biol Pharm Bull 29: 1756-17581, 2006.

18. Zou J, Li Y, Yan CH, Wei FF, Zhang L and Wang JG: Blood pressure in relation to interactions between sodium dietary intake and renal handling. Hypertension 62: 719-725, 2013.

19. Namikoshi T, Tomita N, Fujimoto S, Haruna Y, Ohzeki M, Komai N, Sasaki T, Yoshida A and Kashihara N: Isohumulones derived from hops ameliorate renal injury via an anti-oxidative effect in dahl salt-sensitive rats. Hypertens Res 30: 175-184, 2007.

20. Namikoshi T, Tomita N, Satoh M, Haruna Y, Kobayashi S, Komai N, Sasaki T and Kashihara N: Pioglitazone enhances the antihypertensive and renoprotective effects of candesartan in zucker obese rats fed a high-protein diet. Hypertens Res 31: 745-755, 2008.

21. Reddi AS and Bollineni JS: Selenium-deficient diet induces renal oxidative stress and injury via TGF-betal in normal and diabetic rats. Kidney Int 59: 1342-1353, 2001

22. Kowalski R, Kreft E, Kasztan M, Jankowski M and Szczepanska-Konkel M: Chronic renal denervation increases renal tubular response to $\mathrm{P} 2 \mathrm{X}$ receptor agonists in rats: Implication for renal sympathetic nerve ablation. Nephrol Dial Transplant 27: 3443-3448, 2012.

23. Beevers G, Lip GY and O'Brien E: ABC of hypertension: The pathophysiology of hypertension. BMJ 322: 912-916, 2001.

24. Roman RJ and Cowley AW Jr: Abnormal pressure-diuresis-natriuresis response in spontaneously hypertensive rats. Am J Physiol 248: F199-F205, 1985.

25. Heckmann U, Zidek W and Schurek HJ: Sodium reabsorption in the isolated perfused kidney of normotensive and spontaneously hypertensive rats. J Hypertens Suppl 7: S172-S173, 1989.

26. Vieira-Coelho MA and Moura E: Effect of clonidine on renal sodium handling in spontaneously hypertensive rats. J Pharmacol Sci 119: 122-130, 2012.

27. Katholi RE, Naftilan AJ, Bishop SP and Oparil S: Role of the renal nerves in the maintenance of DOCA-salt hypertension in the rat. Influence on the renal vasculature and sodium excretion. Hypertension 5: 427-435, 1983.

28. Katayama T, Sueta D, Kataoka K, Hasegawa Y, Koibuchi N, Toyama K, Uekawa K, Mingjie M, Nakagawa T, Maeda M, et al: Long-term renal denervation normalizes disrupted blood pressure circadian rhythm and ameliorates cardiovascular injury in a rat model of metabolic syndrome. J Am Heart Assoc 2: e000197, 2013.

29. Healy V, Thompson C and Johns EJ: The adrenergic regulation of proximal tubular $\mathrm{Na}+/ \mathrm{H}+$ exchanger 3 in the rat. Acta Physiol (Oxf) 210: 678-689, 2014

30. DiBona GF: Neural control of the kidney: Functionally specific renal sympathetic nerve fibers. Am J Physiol Regul Integr Comp Physiol 279: R1517-R1524, 2000.

31. Greenberg SG, Enders C and Osborn JL: Renal nerves affect rate of achieving sodium balance in spontaneously hypertensive rats. Hypertension 22: 1-8, 1993.

32. Rogenes PR and Gottschalk CW: Renal function in conscious rats with chronic unilateral renal denervation. Am J Physiol 242: F140-F148, 1982.

33. Rudd MA, Grippo RS and Arendshorst WJ: Acute renal denervation produces a diuresis and natriuresis in young SHR but not WKY rats. Am J Physiol 251: F655-F661, 1986.

34. Oparil S, Sripairojthikoon W and Wyss JM: The renal afferent nerves in the pathogenesis of hypertension. Can J Physiol Pharmacol 65: 1548-1558, 1987.

35. Kline RL: Renal nerves and experimental hypertension: Evidence and controversy. Can J Physiol Pharmacol 65: 1540-1547, 1987.

36. Giebisch G: Renal potassium transport: Mechanisms and regulation. Am J Physiol 274: F817-F833, 1998.

37. Ljutić D and Kes P: The role of arterial hypertension in the progression of non-diabetic glomerular diseases. Nephrol Dial Transplant 18 (Suppl 5): v28-v30, 2003.

38. Petras D, Koutroutsos K, Kordalis A, Tsioufis C and Stefanadis C: The role of sympathetic nervous system in the progression of chronic kidney disease in the era of catheter based sympathetic renal denervation. Curr Clin Pharmacol 8: 197-205, 2013. 
39. Amann K, Nichols C, Tornig J, Schwarz U, Zeier M, Mall G and Ritz E: Effect of ramipril, nifedipine and moxonidine on glomerular morphology and podocyte structure in experimental renal failure. Nephrol Dial Transplant 11: 1003-1011, 1996.

40. Fenton C, Keating GM and Lyseng-Williamson KA: Moxonidine: A review of its use in essential hypertension. Drugs 66: 477-496, 2006.
41. Krespi PG, Makris TK, Hatzizacharias AN, Triposkiadis P, Tsoukala C, Kyriaki D, Votteas V and Kyriakidis M: Moxonidine effect on microalbuminuria, thrombomodulin and plasminogen activator inhibitor-1 levels in patients with essential hypertension. Cardiovasc Drugs Ther 12: 463-467, 1998.

42. Luippold G, Beilharz M and Mühlbauer B: Chronic renal denervation prevents glomerular hyperfiltration in diabetic rats. Nephrol Dial Transplant 19: 342-347, 2004. 